\title{
Posttraumatic growth and cancer: a study 5 years after treatment end
}

\author{
Claudia Cormio $^{1} \cdot$ Barbara Muzzatti $^{2} \cdot$ Francesca Romito $^{1} \cdot$ Vittorio Mattioli $^{1}$ • \\ Maria Antonietta Annunziata ${ }^{2}$
}

Received: 25 July 2016 / Accepted: 11 November 2016 /Published online: 24 December 2016

(C) The Author(s) 2016. This article is published with open access at Springerlink.com

\begin{abstract}
Purpose Cancer survivors often report posttraumatic growth (PTG). The aims of this study were to assess the presence of PTG in Italian long-term disease-free cancer survivors (LCS) and to explore the association between the dimensions of PTG and clinical, demographic variables, various agents of perceived social support and psychological distress.

Methods Five hundred forty LCS were assessed with Posttraumatic Growth Inventory (PTGI), Multidimensional Scale of Perceived Social Support (MSPSS), Zung SelfRating Depression Scale, and State-Trait Anxiety InventoryY (STAI-Y).

Results Mean age was 57.08 years, mean survival was 11.04 years (range 5-32), and the most common cancer diagnosis was breast cancer $(56.9 \%)$. The PTGI average total score was higher in more educated LCS, in those employed, in LCS with longer time from diagnosis, and in those with no comorbidities. In this study, PTG was not found correlated with distress, but it correlated with perceived social support, age, education, and employment.

Conclusions The absence of a correlation between PTG and psychological distress and the low levels of PTG found let us question the importance of talking about PTG when working as psychotherapists with LCS. It may be suggested that the need of finding benefit and PTG in LCS has been overcome by other experiences or worries happened after the cancer, and
\end{abstract}

Francesca Romito

francescaromito@yahoo.com

1 Experimental Unit of Psycho-Oncology, National Cancer Research Centre "Giovanni Paolo II", Bari, Italy

2 Unit of Oncological Psychology, Centro di Riferimento Oncologico - National Cancer Institute, Aviano, PN, Italy
LCS may not focus anymore on positive changes occurred. The relevance of work and of perceived social support as linked to PTG stresses the need to protect the LCS's relationship with work and to promote and sustain their social network, and this can help them to experience sharing and closeness to others.

Keywords Cancer survivors - Posttraumatic growth · Posttraumatic growth dimensions · Social support · Trauma . Psychological distress

\section{Introduction}

In the last decades, many studies have reported positive changes in people who have experienced various traumatic events, such as diseases, natural disasters, and wars. Indeed, in his well-known aphorism, Nietzsche said "What does not kill me, makes me stronger". Along with religion and philosophy, psychology has also dealt with this concept [1, 2], and recently, empirical research has been conducted to better understand the mechanisms which are at the basis of growth as a result of adversity.

Tedeschi and Calhoun $[3,4]$ coined the term posttraumatic growth (PTG), which describes the positive psychological change that can occur as a result of a struggle with highly challenging adverse life events. PTG is what the individual experiences as a result of trauma, in terms of growth beyond her/his previous level of functioning, with eventual lifetyle changes and deeper insight. According to this model, the traumatic event deeply shakes the pre-traumatic mold, disrupting the sense of security and the invulnerability of the individual, their goals, and how they manage emotional stress. Following this emotional earthquake, ruminating activity begins, aimed at the search for meaning with respect to what happened and 
the management of emotions. It seems that individual growth is better expressed in the relational, individual, and philosophy of life fields [5]. At the personal level, the individual perceives an increased sense of self-value, which enables personal resources such as courage, strength, and endurance. As regards with life philosophy, it is observed a greater ability to appreciate the small things and a new scale of priorities. At the relational level, there seems to be greater empathy and greater closeness to others.

This construct is also applicable to cancer, as a traumatic event that breaks the mold of previous life at diagnosis and stands as a watershed between the before and after in the patient's life. Cancer, in fact, places individuals in a life threatening condition that provokes fear of death and suffering and can have a devastating effect on the patient's physical and psychological functioning [6]. Cancer may represent the chance for personal and social enrichment, an experience which is likely to elicit both suffering and growth [7].

Many cancer survivors report positive life changes following cancer diagnosis [8-12]. PTG has been studied in various populations of cancer survivors, and it seems that it has several moderators and associated factors. For example, time passed from diagnosis seems to be an important moderator factor: in the short survival time, a higher growth is linked to a higher distress $[13,14]$. This datum is linked to what Tedeschi and Calhoun [4] have suggested: the more is the event traumatic and shocking for the individual previous beliefs and functioning, the more he/she will experience growth in the short time after the event. The literature reports that the opposite happens in the long term where usually higher growth is linked to higher well-being $[13,14]$.

Even if several studies have reported PTG in cancer survivors, most of them were aimed at young adult survivors of childhood cancer, while very little is known of the PTG in long-term disease-free cancer survivors (LCS) of adult onset cancers $[10,15,16]$.

As regards with the relationship between PTG and psychological well-being, the literature data are conflicting, and there is not enough empirical evidence to confirm which kind of association exists between PTG and distress and/or psychological well-being [17]. For example, there are numerous reports in the literature of a higher growth together with a greater distress [18, 19], but at the same time, other studies showed that experiencing positive changes or PTG influences the psychological adjustment of cancer patients. One of those is the study by Sears et al. [12] that found that 12 months after the end of treatment, higher levels of PTG were associated with increased levels of vigor and positive mood. Furthermore, in a longitudinal study, Carver and Antoni [20] observed that finding benefits from the experience of cancer during the first 12 months after the diagnosis predicted a significant reduction in emotional distress and depression 5 to 8 years later. Despite the lack of consensus on this topic, a study by Stanton [21] reviewed numerous researches and found that PTG is mostly associated with lower levels of emotional distress or better psychological adjustment.

Previous research also suggests that the perception of social support plays an important role in posttraumatic growth development: high levels of posttraumatic growth seem to be associated with high levels of social support [22-24]. Furthermore, Prati and Pietrantoni in a meta-analysis showed a moderate correlation between PTG and social support across different settings for possible trauma [25]. The authors considered that the effects of social support on PTG also vary as a function of who provides the support: social support provided by a spouse or by friends might contribute differently to PTG.

Usually, the researchers consider PTG as one big factor, although different dimensions of growth are traceable. In fact, according to the literature, growth covers five dimensions as measured by the Posttraumatic Growth Inventory [26]: (a) social dimension, which refers to the closeness with others and activation of social resources; (b) cognitive dimension, which concerns feeling stronger and more able to solve problems; (c) emotional dimension, which covers greater compassion for the pain of others, the ability to better express emotions and feelings; (d) physical dimension, which concerns the assumption of a healthy lifestyle; (e) spiritual dimension, which refers to changes in life priorities.

Moreover, as it has already been underlined, few data are present on PTG in LCS of adult onset cancers [10, 15, 16], so we believe that this population deserves to be more thoroughly investigated, and this is one of the objectives of the present study. Furthermore, previous research has mainly focused on the predictors of PTG and, to our knowledge, the relationship between the different dimensions of PTG and clinical, demographic, and psychological variables has not been sufficiently considered.

That said, the aims of this study were the following: (a) to assess the presence of PTG and its dimensions in a large sample of long-term disease-free cancer survivors; (b) to explore the association between the five different dimensions of PTG and clinical, demographic, and psychological variables.

This research is part of an Italian national project funded by the Italian Ministry of Health, which aimed to provide a multidimensional assessment of the mental and physical health of LCS who have been disease-free and treatment-free for at least 5 years.

\section{Methods}

Between 2009 and 2012, 540 LCS were enrolled in the study during their routine annual follow-up visit to the Outpatient Unit at the National Cancer Research Centre, Istituto Tumori "Giovanni Paolo II", Bari and at the Centro di Riferimento Oncologico di Aviano, National Cancer Institute. Survivors 
were eligible to participate if they were the following: (a) 2385 years old (they had to have been $>18$ years old at the time of diagnosis); (b) disease and treatment-free for $\geq 5$ years; (c) able to speak and understand Italian. Six hundred eligible patients were invited to participate in the outpatient waiting room before the follow-up visit. Twenty-one refused to participate, and the other 579 gave written informed consent to participate. Thirty-nine participants provided an incomplete PTGI, so their data were not considered in the study. The study was approved by the ethical committee of the Institutes involved and met the ethical requirements.

\section{Measures}

The survivors completed the questionnaires assessing PTG and perceived social support and psychological distress (i.e., anxiety and depression). Sociodemographic and clinical data (cancer site, time since diagnosis) and comorbidities were also collected.

\section{Posttraumatic Growth Inventory}

The Posttraumatic Growth Inventory (PTGI) [26] consists of a 21-item scale that measures positive outcomes reported by people who have experienced a negative event. It provides separate continuous scores on five dimensions: Relationship with others $(\alpha=0.85)$, New possibilities-purpose $(\alpha=0.84)$, Appreciation of life ( $\alpha=0.67)$, Spiritual change ( $\alpha=0.85$ ), and Personal strength $(\alpha=0.72)$. Survivors used a Likert scale ranging from 0 (no change as a consequence of cancer experience) to 5 (high change as a result of cancer experience) to respond to each item. The scale appears to be useful in determining how successful individuals are in reconstructing or strengthening their perceptions of self, others, and the meaning of events in the aftermath of a traumatic event. The Italian validation was provided by Prati and Pietrantoni [27].

\section{Multidimensional Scale of Perceived Social Support}

The Multidimensional Scale of Perceived Social Support (MSPSS) [28] is a 12-item scale that measures perceived support from family, friends, and a significant other. Respondents answered items on a seven-point Likert-type scale (very strongly disagree to very strongly agree). Also, this tool has been validated in Italian [29].

\section{Zung Self-Rating Depression Scale}

The Zung Self-Rating Depression Scale [30] is a measure of depression. Scores are proportional to depression intensity; scores 50-59, 60-69, and 70+ indicate mild, moderate, and severe depression, respectively. Even if this tool has been designed in 1965, it has been recently validated in Italian by Innamorati et al. [31] and gives the possibility to make comparison with healthy peers and to define cutoff for discriminating who needs psychological help.

\section{State-Trait Anxiety Inventory-Y (STAI-Y)}

This is a self-assessment questionnaire developed to measure state anxiety (Y1) and trait anxiety (Y2) [32]. Subjects are asked to rank different statements on a Likert scale $(1=$ not at all and $4=$ very much) to represent their own behavior. The items are grouped into two scales of 20 questions each, focused on how individuals feel generally, or instead what they feel at particular times. The questionnaire was validated in Italian [33].

\section{Statistical analysis}

Descriptive statistics for PTG and all other psychological variables were calculated.

One sample $t$ test was performed to compare PTG score with the mean value reported by Prati and Pietrantoni [27] for a large $(N=1244)$ sample of Italian adults who had experienced a range of adverse life events.

To test the association between PTG and the collected sociodemographic and clinical data (i.e., gender, age, schooling, occupational status, marital status, type of cancer, length of survivorship, and presence or absence of other health issues), the Mann-Whitney or Kruskal-Wallis test was performed. To test the association between PTG and the collected psychological variables (i.e., state and trait anxiety, depression, perceived social support as provided by friends, the family, and a significant other), Spearman correlations were calculated.

A Friedman test using the five PTG dimensions as dependent variables was performed to verify differences within subjects. A subsequent analysis was performed to identify the statistically significant paired comparisons by means of Wilcoxon signed rank tests and Bonferroni adjustment for multiple comparisons. For these analyses, scores of each PTG component were calculated as the mean of their relative items with a range $0-5$. Furthermore, Mann-Whitney tests, Kruskal-Wallis test, and Spearman correlations were calculated to verify the association of each PTG component with the considered sociodemographic, clinical, and psychological variables (as described above).

Since PTG scores were not normally distributed in our sample [Shapiro-Wilk $(540)=0.977 ; p<0.001$ ], we performed mostly non-parametric statistics. The $p$ value $<0.05$ was preset for statistical significance (two tails). Bonferroni's adjustment of $p$ value was used, when appropriate, to avoid errors due to multiple comparisons. 
All statistical analyses were performed using SPSS software, Version 21 (SPSS Inc., Chicago, Ill.).

\section{Results}

\section{Sample sociodemographic, clinical, and psychological characteristics}

As shown in Table 1, the final sample comprised 540 participants, and $76.9 \%$ of whom were female. The mean age was 57.08 years $(\mathrm{SD}=10.96$; age ranging from 25 to 80 ), and $40.5 \%$ of participants had a post-compulsory education (i.e., had attended school for more than 8 years). The majority of participants in the sample had a non-employed status of retired, homemaker, or unemployed $(70.2 \%)$ and had a stable emotional relationship, noted as married or cohabiting (77\%).

In terms of clinical data, the most common cancer diagnosis was breast cancer $(56.9 \%)$. The mean survivorship was 11.04 years $(\mathrm{SD}=5.12$; survivorship ranging from 5 to 32 ), and $89 \%$ of the sample reported other health issues.

Finally, concerning the psychological variables, perceived social support provided by family was $6.04(\mathrm{SD}=1.25)$, perceived social support provided by friends was 4.67 $(\mathrm{SD}=1.98)$, and perceived social support provided by a significant other was $6.10(\mathrm{SD}=1.33)$. The mean score of state anxiety was $42.69(\mathrm{SD}=11.88)$, trait anxiety was 42.29 $(\mathrm{SD}=10.48)$, and depression was $46.65(\mathrm{SD}=13.04)$.
Table 1 Posttraumatic growth according to sample characteristics: M (DS)

\begin{tabular}{|c|c|c|c|}
\hline & Number & Percentage & Mean (standard deviation) \\
\hline \multicolumn{4}{|l|}{ Gender } \\
\hline Male & 125 & 23.1 & $40.19(25.56)$ \\
\hline $\begin{array}{l}\text { Female } \\
p=0.466\end{array}$ & 415 & 76.9 & $41.77(25.10)$ \\
\hline \multicolumn{4}{|l|}{ Age (years) } \\
\hline $25-39$ & 39 & 7.3 & $48.15(25.98)$ \\
\hline $40-49$ & 89 & 16.6 & $52.33(25.12)$ \\
\hline $50-59$ & 170 & 31.7 & $43.04(24.52)$ \\
\hline $60-69$ & 169 & 31.5 & $37.67(24.67)$ \\
\hline $\begin{array}{l}70+ \\
p<0.001\end{array}$ & 70 & 13.0 & $30.03(20.79)$ \\
\hline \multicolumn{4}{|l|}{ Education } \\
\hline $\begin{array}{l}\text { Compulsory } \\
\text { ( }<9 \text { years) }\end{array}$ & 287 & 59.5 & $39.76(25.39)$ \\
\hline $\begin{array}{l}\text { Post-compulsory } \\
\text { (9+ years) } \\
p=0.006\end{array}$ & 195 & 40.5 & $46.22(24.54)$ \\
\hline \multicolumn{4}{|l|}{ Occupational status } \\
\hline Employed & 160 & 29.8 & $48.13(25.50)$ \\
\hline $\begin{array}{l}\text { Unemployed } \\
p<0.001\end{array}$ & 377 & 70.2 & $38.35(24.39)$ \\
\hline \multicolumn{4}{|l|}{ Marital status } \\
\hline Partnered & 415 & 77.0 & $41.12(25.01)$ \\
\hline $\begin{array}{l}\text { Non-partnered } \\
p=0.689\end{array}$ & 124 & 23.0 & $42.41(25.96)$ \\
\hline \multicolumn{4}{|l|}{ Cancer diagnosis } \\
\hline Breast & 307 & 56.9 & $38.98(24.67)$ \\
\hline Colon-rectum & 48 & 8.9 & $40.71(25.03)$ \\
\hline Lymphoma & 114 & 21.1 & $49.75(25.20)$ \\
\hline Urogenital & 37 & 6.9 & $38.76(25.87)$ \\
\hline $\begin{array}{l}\text { Other } \\
p=0.003\end{array}$ & 34 & 6.2 & $39.12(24.89)$ \\
\hline \multicolumn{4}{|l|}{$\begin{array}{l}\text { Survivorship length } \\
\text { (years) }\end{array}$} \\
\hline$<10$ & 268 & 49.6 & $38.95(23.96)$ \\
\hline $\begin{array}{l}10+ \\
p=0.042\end{array}$ & 272 & 50.4 & $43.82(26.17)$ \\
\hline \multicolumn{4}{|l|}{$\begin{array}{l}\text { Presence of other } \\
\text { health issues }\end{array}$} \\
\hline Yes & 419 & 89.0 & $39.92(25.20)$ \\
\hline $\begin{array}{l}\text { No } \\
p=0.014\end{array}$ & 52 & 11.0 & $49.02(26.10)$ \\
\hline Total & 540 & 100.0 & $41.40(25.19)$ \\
\hline
\end{tabular}

Sums may not add up to total because of missing values 


\section{Posttraumatic growth}

In the present sample, the total score of PTG was 41.40 $(\mathrm{SD}=25.19)$. This score was significantly lower than that of Italian adults who had experienced a range of adverse life events $[t(539)=-3.30 ; p=0.001 ; 95 \%$ confidence interval of the difference: $-5.71 ;-1.45]$.

As shown in Table 1, more educated participants $(z=-2.76 ; p=0.006)$, employed participants $(z=-4.24$; $p<0.001)$, participants surviving cancer for ten or more years $(z=-2.04 ; p=0.042)$, and participants not reporting other health issues $(z=-2.45 ; p=0.014)$ displayed higher scores than their counterparts. In addition, there were statistically significant associations with age $\left[\mathrm{chi}^{2}(4)=39.56 ; p<.001\right]$ and cancer type $\left[\mathrm{chi}^{2}(4)=15.67 ; p=0.003\right]$. In particular, 40 49-year-old participants displayed higher scores than all the three older age groups $(p<0.005)$, and both the youngest age group (25-39 years) and the 50-59-year-old participants displayed higher scores than 70+-year-old participants $(p<0.005)$. Similarly, lymphoma survivors displayed higher scores than breast cancer survivors $(p<0.001)$. Conversely, there were no differences related to gender $(z=0.73$; $p=0.466)$ or having a stable emotional relationship $(z=0.40 ; p=0.689)$.

PTG was found to be positively correlated to the perceived social support as provided by friends $(p<0.001)$, the perceived social support as provided by family $(p=0.005)$, and the perceived social support as provided by a significant other $(p<0.001)$, but it was not correlated to state anxiety $(p=0.488)$, trait anxiety $(p=0.834)$, or depression $(p=0.081)($ Table 2).

\section{Posttraumatic growth dimensions}

Table 3 displays mean, standard deviation, and minimum and maximum for the five dimensions of PTG. Compared with a large sample of Italian adults who had experienced a range of adverse life events [27], the present sample displayed lower scores in the following dimensions: Relating to others $[t(539)=-2.26 ; p=0.024 ; 95 \%$ confidence interval of the difference: $-0.25 ;-0.02]$ and in New possibilities $[t(539)=-10.42 ; p<0.001 ; 95 \%$ confidence interval of the difference: $-0.69 ;-0.47]$. This sample also displayed higher scores in Personal strength $[t(539)=3.66 ; p<0.001 ; 95 \%$ confidence interval of the difference: $0.11 ; 0.36]$ and Spiritual changes $[t(539)=2.73 ; p=0.007 ; 95 \%$ confidence interval of the difference: $0.06 ; 0.38]$, but no differences were found in Appreciation for life $[t(539)=1.04 ; p=0.300 ; 95 \%$ confidence interval of the difference: $-0.06 ; 0.20]$.

Statistically significant differences in PTG component scores within subjects were found by a Friedman test $\left[\operatorname{chi}^{2}(4)=358.53 ; p<0.001\right]$. The subsequent analysis showed Appreciation of life to be higher than all the other four PTG dimensions $(p<0.001)$; Personal strength was lower than Appreciation of life and higher than the other three dimensions $(p<0.001)$; Spiritual change was lower than both Appreciation of life and Personal strength, but higher than New possibilities $(p<0.001)$; Relating to other was lower than both Appreciation for life and Personal strength, but higher than New possibilities $(p<0.001)$. New possibilities was the component with the lowest score $(p<0.001)$.

Tables 4 and 5 report data for the five PTG dimensions separately.

In Relating to others, employed participants $(z=-3.60$; $p<0.001)$ and participants declaring no other health issues $(z=-2.65 ; p=0.008)$ displayed higher scores than their counterparts. In addition, this PTG component was significantly associated with age $\left[\mathrm{chi}^{2}(4)=24.05 ; p<0.001\right]$ and cancer type $\left[\operatorname{chi}^{2}(4)=15.71 ; p=0.003\right]$. In particular, 40-49-year-old participants displayed higher scores than both the 50-59 and $70+$ age groups $(p<0.001)$, and lymphoma survivors displayed higher scores than breast cancer survivors $(p<0.001)$. Finally, Relating to others correlated positively with perceived social support as provided by the family $(p=0.002)$, by friends $(p<0.001)$, and by a significant other $(p<0.001)$.

In New possibilities, more educated participants $(z=-4.25$; $p<0.001)$, employed participants $(z=-5.71 ; p<0.001)$, participants surviving cancer for more years $(z=-3.33$; $p=0.001$ ), and participants declaring no other health issues $(z=-3.16 ; p=0.002)$ displayed higher scores than their counterparts. In addition, this PTG component was significantly associated with age $\left[\mathrm{chi}^{2}(4)=51.25 ; p<0.001\right]$ and cancer type $\left[\operatorname{chi}^{2}(4)=29.79 ; p<0.001\right]$. In particular, both the 25-39 and 40-49 age groups showed higher scores than the 60-69 and $70+$ years age groups $(p<0.001)$, and the intermediate age group (50-59 years) showed higher scores than the oldest
Table 2 Spearman correlations between posttraumatic growth and anxiety, depression, and perceived social support

\begin{tabular}{lllllll}
\hline & $\begin{array}{l}\text { Trait } \\
\text { anxiety }\end{array}$ & $\begin{array}{l}\text { State } \\
\text { anxiety }\end{array}$ & Depression & $\begin{array}{l}\text { PSS by } \\
\text { family }\end{array}$ & $\begin{array}{l}\text { PSS by } \\
\text { friends }\end{array}$ & $\begin{array}{l}\text { PSS by a } \\
\text { significant } \\
\text { other }\end{array}$ \\
\hline $\begin{array}{c}\text { Posttraumatic } \\
\text { growth }\end{array}$ & 0.010 & -0.34 & -0.077 & $0.137+$ & $0.270 \#$ & $0.194 \#$ \\
\hline
\end{tabular}

$+p<0.01 ; \# p<0.001$ 
Table 3 Posttraumatic growth dimensions

\begin{tabular}{llllll}
\hline Factor & No. of items & Mean & Standard deviation & Minimum & Maximum \\
\hline Relating to others & 7 & 1.88 & 1.38 & 0 & 5 \\
New possibilities & 5 & 1.50 & 1.3 & 0 & 5 \\
Personal strength & 4 & 2.27 & 1.47 & 0 & 5 \\
Spiritual change & 2 & 1.89 & 1.86 & 0 & 5 \\
Appreciation of life & 3 & 2.62 & 1.58 & 0 & 5 \\
\hline
\end{tabular}

one $(p<0.001)$, and lymphoma survivors displayed higher scores than breast cancer survivors $(p<0.001)$. Finally, New possibilities was negatively correlated to state anxiety $(p=0.006)$ and depression $(p<0.001)$ and was positively correlated to perceived social support as provided by friends $(p<0.001)$ and a significant other $(p=0.048)$.

In Personal strength, employed participants $(z=-3.19$; $p=0.001)$ displayed higher scores than their counterparts. In
Table 4 Posttraumatic growth dimensions according to sample characteristics (M [DS])

\begin{tabular}{|c|c|c|c|c|c|}
\hline & RO & NP & PS & $\mathrm{SC}$ & $\mathrm{AL}$ \\
\hline \multicolumn{6}{|l|}{ Gender } \\
\hline Male & $1.82(1.28)$ & $1.70(1.45)$ & $2.16(1.41)$ & $1.35(1.67)$ & $2.56(1.45)$ \\
\hline Female & $1.91(1.40)$ & $1.44(1.25)$ & $2.30(1.48)$ & $2.05^{*}(1.88)$ & $2.64(1.61)$ \\
\hline \multicolumn{6}{|l|}{ Age (years) } \\
\hline $25-39$ & $2.14(1.33)$ & $2.17(1.48)$ & $2.67(1.48)$ & $1.55(1.76)$ & $2.92(1.43)$ \\
\hline $40-49$ & $2.45(1.33)$ & $2.15(1.36)$ & $2.67(1.43)$ & $2.16(1.91)$ & $3.16(1.43)$ \\
\hline $50-59$ & $1.87 *(1.43)$ & $1.54 *(1.28)$ & $2.48 *(1.44)$ & $1.97(1.91)$ & $2.78^{*}(1.58)$ \\
\hline $60-69$ & $1.72(1.31)$ & $1.24(1.21)$ & $2.04(1.45)$ & $1.94(1.89)$ & $2.45(1.61)$ \\
\hline $70+$ & $1.53(1.28)$ & $0.85(0.79)$ & $1.66(1.29)$ & $1.40(1.58)$ & $1.86(1.36)$ \\
\hline \multicolumn{6}{|l|}{ Education } \\
\hline $\begin{array}{l}\text { Compulsory } \\
\text { ( }<9 \text { years })\end{array}$ & $1.85(1.40)$ & $1.35(1.26)$ & $2.17(1.48)$ & $2.03(1.89)$ & $2.44(1.58)$ \\
\hline $\begin{array}{l}\text { Post-compulsory } \\
\text { (9+ years) }\end{array}$ & $2.03(1.34)$ & $1.86^{*}(1.36)$ & $2.51(1.40)$ & $1.81(1.82)$ & $3.04^{*}(1.45)$ \\
\hline \multicolumn{6}{|l|}{ Occupational status } \\
\hline Employed & $2.20(1.35)$ & $2.01(1.39)$ & $2.57(1.45)$ & $1.74(1.78)$ & $2.99(1.50)$ \\
\hline Unemployed & $1.74^{*}(1.36)$ & $1.27^{*}(1.19)$ & $2.13^{*}(1.45)$ & $1.91(1.88)$ & $2.46^{*}(1.58)$ \\
\hline \multicolumn{6}{|l|}{ Marital status } \\
\hline Partnered & $1.87(1.38)$ & $1.46(1.26)$ & $2.29(1.48)$ & $1.85(1.84)$ & $2.64(1.60)$ \\
\hline Non-partnered & $1.95(1.37)$ & $1.65(1.44)$ & $2.21(1.44)$ & $2.00(1.90)$ & $2.54(1.49)$ \\
\hline \multicolumn{6}{|l|}{ Cancer diagnosis } \\
\hline Breast & $1.76(1.40)$ & $1.28(1.16)$ & $2.21(1.49)$ & $1.98(1.91)$ & $2.49(1.65)$ \\
\hline Colon-rectum & $1.88(1.41)$ & $1.43(1.23)$ & $2.31(1.40)$ & $1.94(1.68)$ & $2.48(1.57)$ \\
\hline Lymphoma & $2.30 *(1.26)$ & $2.15^{*}(1.48)$ & $2.57(1.43)$ & $1.79(1.70)$ & $3.01(1.33)$ \\
\hline Urogenital & $1.79(1.28)$ & $1.60(1.43)$ & $1.90(1.44)$ & $1.58(1.91)$ & $2.50(1.53)$ \\
\hline Other & $1.75(1.41)$ & $1.27(1.12)$ & $2.17(1.37)$ & $1.68(2.09)$ & $2.85(1.61)$ \\
\hline \multicolumn{6}{|l|}{$\begin{array}{l}\text { Survivorship length } \\
\text { (years) }\end{array}$} \\
\hline$<10$ & $1.80(1.38)$ & $1.29(1.16)$ & $2.17(1.41)$ & $1.90(1.82)$ & $2.50(1.60)$ \\
\hline $10+$ & $1.97(1.37)$ & $1.71^{*}(1.40)$ & $2.37(1.52)$ & $1.87(1.89)$ & $2.74(1.55)$ \\
\hline \multicolumn{6}{|l|}{$\begin{array}{l}\text { Presence of other } \\
\text { health issues }\end{array}$} \\
\hline Yes & $1.81(1.38)$ & $1.42(1.29)$ & $2.20(1.48)$ & $1.86(1.87)$ & $2.53(1.60)$ \\
\hline No & $2.31^{*}(1.26)$ & $2.14^{*}(1.50)$ & $2.44(1.43)$ & $1.67(1.73)$ & $3.02(1.37)$ \\
\hline
\end{tabular}

$R O$ Relating to others, $N P$ New possibilities, $P S$ Personal strength, $S C$ Spiritual changes, $A L$ Appreciation for life ${ }^{*} p$ value was statistically significant according to Bonferroni's correction: $p<0.05 / 5$ 
Table 5 Spearman correlations between PTG dimensions and anxiety, depression, and perceived social support

\begin{tabular}{lllllll}
\hline & $\begin{array}{l}\text { Trait } \\
\text { anxiety }\end{array}$ & $\begin{array}{l}\text { State } \\
\text { anxiety }\end{array}$ & Depression & $\begin{array}{l}\text { PSS by } \\
\text { family }\end{array}$ & $\begin{array}{l}\text { PSS by } \\
\text { friends }\end{array}$ & $\begin{array}{l}\text { PSS by a } \\
\text { significant } \\
\text { other }\end{array}$ \\
\hline $\begin{array}{c}\text { Relating to } \\
\text { others }\end{array}$ & -0.045 & -0.008 & -0.034 & $0.153+$ & $0.288 \#$ & $0.206 \#$ \\
$\begin{array}{c}\text { New } \\
\text { possibilities }\end{array}$ & -0.085 & $-0.134+$ & $-0.152 \#$ & 0.058 & $0.228 \#$ & $0.097^{*}$ \\
$\begin{array}{c}\text { Personal } \\
\text { strength }\end{array}$ & -0.041 & -0.050 & $-0.132+$ & $0.167+$ & $0.235 \#$ & $0.179 \#$ \\
$\begin{array}{c}\text { Spiritual change } \\
\text { Appreciation of }\end{array}$ & $0.108^{*}$ & -0.91 & $0.096^{*}$ & $0.101^{*}$ & 0.075 & $0.113^{*}$ \\
$\quad-0.017$ & -0.035 & -0.072 & 0.086 & $0.220 \#$ & $0181 \#$ \\
\hline life & & & & & & \\
\hline
\end{tabular}

$* p<0.05 ;+p<0.01 ; \# p<0.001$

addition, this PTG component was significantly associated with age $\left[\mathrm{chi}^{2}(4)=29.20 ; p<0.001\right]$. In particular, both the 40-49 and 50-59 age groups reported higher scores than the oldest one $(p<0.001)$. Finally, Personal strength was negatively correlated to depression $(p=0.003)$, and it was positively correlated to perceived social support provided by the family $(p=0.001)$, friends $(p<0.001)$, and a significant other $(p<0.001)$.

In Spiritual changes, females displayed higher scores than males $(z=-3.60 ; p<0.001)$. In addition, Spiritual changes was positively correlated to trait anxiety $(p=0.027)$, depression $(p=0.028)$, perceived social support as provided by the family ( $p=0.040$ ), and perceived social support as provided by a significant other $(p=0.021)$.

In Appreciation for life, more educated participants $(z=-4.09 ; p<0.001)$ and employed participants $(z=-3.62$; $p<0.001)$ displayed higher scores than their counterparts. In addition, this PTG component was significantly associated with age $\left[\mathrm{chi}^{2}(4)=32.39 ; p<0.001\right]$, where the $25-39,40$ 59 , and 50-59 age groups showed higher scores than the oldest age group $(p<0.001)$. Finally, Appreciation for life was positively correlated to perceived social support as provided by friends $(p<0.001)$ and a significant other $(p<0.001)$.

\section{Discussion}

This cross-sectional study examined the posttraumatic growth of a large sample of long-term and disease-free cancer survivors, and to the best of our knowledge, it is one of the few research efforts so far to have focused on cancer-related growth over three decades after diagnosis.

Also, as few studies have examined PTG and its dimensions in detail, our study offers new insights into this phenomenon [34].

The first interesting finding of our study is the total score of posttraumatic growth, which was significantly lower than that of Italian adults who had experienced a range of adverse life events.

One possible explanation of this finding is that people whose cancer experience happened a decade or more before may have integrated the cancer-related changes into their personality. Meanwhile, other events may have occurred in people's lives, so as to reduce the meaning of cancer in their lifetime. Another possible explanation can be based on the perception of cancer as a long-lasting experience rather than a concluded life episode [9]. Studies monitoring well-being and functioning of this specific population could help in understanding the reason for this datum.

\section{Associations between posttraumatic growth dimensions and study variables}

Among the study variables that correlate more closely with PTG were perceived social support, as provided by three different sources, age, education, and employment.

In our sample, all the PTG dimensions correlated with perceived social support provided by family, friends, and significant others. Consistent with these findings, there is a previous longitudinal research exploring which kind of support is more related to PTG, finding that emotional support actually received from others is related to PTG also many years after diagnosis [35]. The support of close people and the possibility to talk with them can arouse new cognitive processes and booster coping responses that may in turn promote positive changes. Mechanisms implicated may be both cognitive and emotional: emotional support and talking with others may offer new perspectives on the traumatic event. On the other hand, other people may give encouragement and positive reinforcement with respect to how the patient is addressing the difficulty contributing to his/her self-esteem and sense of mastery [36, 37].

Younger age was associated with four dimension of posttraumatic growth, except for Spiritual change, confirming previous literature findings [11,32]. This could be due to the fact that younger people have expectation of longer life and 
planning skills that may help them to better enjoy the present and prepare for the future life. It has also been suggested by Tedeschi and Calhoun themselves [4] that the more is the traumatic event shocking for the individual previous functioning and the more it is disrupting his/her previous identity (e.g., sense of immortality, expectations on the future, which are more present in younger people), the more the person may develop internal sense of growth after the trauma. Moreover, often the elderly are more involved in the management of other stressful life events, such as other comorbidities and bereavement than younger people. On this note, in our sample, participants not reporting other health issues showed a higher level of PTG. This consideration was also supported by the findings of a study conducted by Bellizzi [38] that showed that elderly survivors of breast cancer were less worried by their diagnosis due to the presence of other painful life events (death of a spouse, visual or hearing impairment etc.).

All PTG dimensions showed correlation to employment, except Spiritual change. This result is in line with those reported by Bellizzi and Blank, namely, that the survivors employed full- or part-time showed higher levels of PTG [39]. Work could be a protective factor against stress [40] helping people to focus on various life goals and to find meaning deriving also from their professional life.

To what concerns the correlation between PTG and education, we have found that the two dimensions that are more implicated are New possibilities and Appreciation for life. We can speculate that having a high level of education is a positive resource with respect to the ability to overcome the psychosocial difficulties related to oncological disease. In fact, Ross et al. reported that people with a higher level of education have more ease in the construction of social relations, which are characterized by greater stability. From this, it arises the possibility of a better social support. [41].

In our sample, Spiritual change behaved differently from other dimensions: unlike the others, it did not correlate with age and employment, but it was the only PTG dimension positively correlated with gender (women showed higher results than men) and with anxiety and depression. Survivors who are more depressed and have a higher level of trait anxiety reported more change in this dimension, as if they try and find support in spirituality more than others with less psychological symptoms. This seems like a kind of outsourcing.

We were also interested in evaluating the relationship between psychological distress, i.e., a cancer-specific psychological effect and PTG.

In our sample, PTG as a general construct was not correlated to depression or to anxiety, as underlined in previous research $[10,13]$, but a negative correlation was found with depression and the dimensions "new possibilities" and "personal strength": if other research has found a correlation between PTG and depression, this can be linked to the fact that in the short term, people still feel confusion related to the disruption of previous certainties [18, 19], which may be overcome in the long-term period, which is the case of the present study population.

The findings of the present study provide interesting insights for therapeutic work with cancer patients and cancer survivors: the absence of a correlation between posttraumatic growth and psychological distress (depression and anxiety) and the same datum of low levels of posttraumatic growth in this population of long-term cancer survivors let us question the importance of talking about posttraumatic growth when working as psychotherapists with persons that have lived the cancer experience many years before. It may be suggested that for LCS, the construct of PTG has been overcome by other experiences or worries happened in the years after the end of treatments, and they did not focus anymore so much on positive changes occurred after the trauma. Probably the PTG may better work as a sort of coping strategy, as one way to make sense of a traumatic experience right or short after the cancer experience has occurred, in order to help the individual to find a meaning and a positive interpretation of the illness experience.

On the other hand, when treating patients still in treatment or in the short period of survival, the concept of PTG may bring an interesting clinical perspective in the clinical setting that allows the psychotherapist and the oncologist to see distress, disbelief, and the patient's pain not only as a maladaptive response but also as possible growth factors [42].

The important information obtained regarding the relevance of work, for example, stress the need not to marginalize cancer survivors due to their cancer experience but rather to protect their relationship with work.

Furthermore, the strong relationship between perceived social support and PTG suggests that clinicians should look carefully at the social context of the survivors and promote and sustain the creation of a social network that can help them to experience sharing and closeness to others, rather than loneliness. This could be particularly adapt for the cultural context where the study has been carried out: people in Italy are used to rely on partners and extended family members as important source of support. This kind of support, also in the present work, has been shown important to help the individual to cognitively and emotionally find meaning out of the cancer experience and developing new perspectives of growth.

Limitations of the present study regard the cross-sectional design that did not allow us to draw conclusion of the causal relationship between the variables under study. Furthermore, the present study did not investigate any further crucial life events of cancer survivors (positive or negative) that could have affected the results and the development of posttraumatic growth, in relation to the event cancer. Then, in future research, it would be useful to evaluate this aspect in order to understand whether survivors who have been exposed to 
significant life events after the cancer may have reduced the significance of the cancer experience in their personal life. Moreover, for future research, it would be useful to consider whether the Italian culture has some specificities in the dimensions of the PTG that the PTGI does not completely capture.

Acknowledgements This work was supported by the Italian Ministry of Health that funded the Integrated Research Program in Oncology no. 7 "Medical and psycho-social rehabilitation program for long-term cancer survivors".

The authors wish to thank Dr. Caroline Oakley for her valuable assistance during the linguistic revision of the paper.

Compliance with ethical standards This research is part of an Italian national project funded by the Italian Ministry of Health, which aimed to provide a multidimensional assessment of the mental and physical health of LCS who have been disease-free and treatment-free for at least 5 years. The study was approved by the ethical committee of the Institutes involved and met the ethical requirements.

Disclosures None.

Conflict of interest The authors declare that they have no conflict of interest.

Open Access This article is distributed under the terms of the Creative Commons Attribution-NonCommercial 4.0 International License (http:// creativecommons.org/licenses/by-nc/4.0/), which permits any noncommercial use, distribution, and reproduction in any medium, provided you give appropriate credit to the original author(s) and the source, provide a link to the Creative Commons license, and indicate if changes were made.

\section{References}

1. Magrin ME, Scrignaro M, Steca P (2007) La sfida delle avversità: minaccia o transizioni di crescita? Psicologia della salute 1:11-32

2. Tedeschi RG, Park CL, Calhoun LG (1998) Posttraumatic growth: conceptual issues. In: Tedeschi RG, Park CL, Calhoun LG (eds) Posttraumatic growth: positive changes in the aftermath of crisis. Lawrence Erlbaum Ass, Mahwah, pp. 1-22

3. Tedeschi R, Calhoun L (1995) Trauma and transformation: growing in the aftermath of suffering. Sage Publications, Thousand Oaks

4. Tedeschi R, Calhoun L (2004) Posttraumatic growth: conceptual foundations and empirical evidence. Psychological Inquiry Psychological Inquiry 15:1-18. doi:10.1207/s15327965 pli1501 01

5. Joseph S, Linley PA (2006) Growth following adversity: theoretical perspectives and implications for clinical practice. Clin Psychol Rev 26(8):1041-1053. doi:10.1016/j.cpr.2005.12.006

6. Gallagher J, Parle M, Cairns D (2002) Appreciation and psychological distress six months after diagnosis of breast cancer. Br J Healt Psychol 7(3):365-376. doi:10.1348/135910702760213733

7. Andrykowsky MA, Curran SL, Studts JL, Cunningham L, Carpenter JS, McGrath PC, Kenady DE (1996) Psychosocial adjustment and quality of life in women with breast cancer and benign breast problems: a controlled comparison. J Clin Epidemiol 49(8): 827-834

8. Lelorain S, Bonnaud-Antignac A, Florin A (2010) Long term posttraumatic growth after breast cancer: prevalence, predictors and relationships with psychological health. J Clin Psychol Med Settings 17:14-22. doi:10.1007/s10880-009-9183-6

9. Cormio C, Romito F, Giotta F, Mattioli V (2015) Post-traumatic growth in the Italian experience of long-term disease-free cancer survivors. Stress Health 31:189-196. doi:10.1002/smi.2545

10. Cordova MJ, Cunningham LLC, Carlson CR, Andrykowsky MA (2001) Posttraumatic growth following breast cancer: a controlled comparison study. Health Psychol 20(3):176-185

11. Tomich PL, Helgeson VS, Nowak Vache EJ (2005) Perceived growth and decline following breast cancer: a comparison to agematched controls 5-years later. Psycho-Oncology 14(12):1018 1029. doi:10.1002/pon.914

12. Sears SR, Stanton AL, Danoff-Burg S (2003) The yellow brick road and the emerald city: benefit finding, positive re-appreciation, and posttraumatic growth in women with early-stage breast cancer. Health Psychol 22(5):487-497. doi:10.1037/0278-6133.22.5.487

13. Helgeson VS, Reynolds KA, Tomich PL (2006) A meta-analytic review of benefit findings and growth. J Consul Clin Psychol 74: 797-816. doi:10.1037/0022-006X.74.5.797

14. Sawyer A, Ayers S, Field AP (2010 Jun) Posttraumatic growth and adjustment among individuals with cancer or HIV/AIDS: a metaanalysis. ClinPsychol Rev 30(4):436-447. doi:10.1016/j. cpr.2010.02.004

15. Jansen L, Hoffmeister M, Chang-Claude J, Brenner H, Arndt V (2011) Benefit finding and posttraumatic growth in long-term colorectal cancer survivors: prevalence, determinants, and associations with quality of life. Br J Cancer 105:1158-1165. doi:10.1038/bjc.2011.335

16. Ho SMY, Chan CLW, Ho RTH (2004) Posttraumatic growth in Chinese cancer survivors. Psycho-Oncology 13:377-389. doi:10.1002/pon.758

17. Sumalla EC, Ochoa C, Blanco I (2009) Posttraumatic growth in cancer: reality or illusion? Clin Psychol Rev 29(1):24-33. doi:10.1016/j.cpr.2008.09.006

18. Barakat LP, Alderfer MA, Kazak AE (2006) Posttraumatic growth in adolescent survivors of cancer and their mothers and fathers. J Pediatr Psychol 31:413-419. doi:10.1093/jpepsy/jsj058

19. Bellizzi KM, Smith AW, Reeve BB et al (2010) Posttraumatic growth and health-related quality of life in a racially diverse cohort of breast cancer survivors. J Health Psychol 15:615-626

20. Carver CS, Antoni MH (2004) Finding benefit in breast cancer during the year after diagnosis predicts better adjustment 5 to 8 years after diagnosis. Health Psychol 23(6):595-598

21. Stanton AL (2006) Psychosocial concerns and interventions for cancer survivors. J Clin Oncol 24(32):5132-5137. doi:10.1200/JCO.2006.06.8775

22. Northouse LL (1988) Social support in patients' and husbands' adjustment to breast cancer. Nurs Res 37(2):91-95

23. Holland KD, Holahan CK (2003) The relation of social support and coping to positive adaptation to breast cancer. Psychol Health 18: 15-29. doi: $10.1080 / 0887044031000080656$

24. Thornton AA (2002) Perceiving benefit in the cancer experience. J ClinPsychol Med S 90(2):153-165

25. Prati G, Pierantoni L (2009) Optimism, social support, and coping strategies as factors contributing to posttraumatic growth: a meta-analysis. J Loss Trauma 14(5):364-388. doi:10.1080/15325020902724271

26. Tedeschi RG, Calhoun LG (1996) The Posttraumatic Growth Inventory: measuring the positive legacy of trauma. J Trauma Stress 9(3):455-471

27. Prati G, Pietrantoni L (2014) Italian adaptation and confirmatory factor analysis of the full and the short form of the Posttraumatic Growth Inventory. J loss trauma 19(1):12-22. doi:10.1080/15325024.2012.734203 
28. Zimet GD, Dahlem NW, Zimet SG, Farley GK (1988) The multidimensional scale of perceived social support. J Pers Assess 52(1): 30-41

29. Prezza M, Santinello M (2002) Conoscere la comunità. Il Mulino, Bologna

30. Zung WW (1965) A self-rating depression scale. Arch Gen Psychiatry 12:63-70

31. Innamorati M, Lelli M, Aiello S, Ferrari V (2006) Convergent and discriminant validation of the Italian version of the Zung self-rating depression scale. PsicoterapiaCognitiva e Comportamentale 12(3): 343-353

32. Spielberger CD, Gorsuch RL, Lushene R, Vagg PR, Jacobs GA (1983) Manual for the state-trait anxiety inventory. Consulting Psychologists Press, Palo Alto

33. Pedrabissi L, Santinello M (1989) Inventario per l'Ansia di 'Stato' e di 'Tratto': Nuova Versione Italiana dello STAI - Forma Y: Manuale (In Italian). Organizzazioni Speciali, Firenze

34. Lechner SC, Zakowski SG, Antoni MH, Greenhawt M, Block K, Block P (2003) Do sociodemographic and disease-related variables influence benefit finding in cancer patients? Psycho-Oncology 12: 491-499. doi:10.1002/pon.671

35. Schoevers MJ, Helgeson VS, Sanderman R, Ranchor AV (2010) Type of social support matters for prediction of posttraumatic growth among cancer survivors. Psycho-Oncology 19:46-53. doi:10.1002/pon.1501

36. Thoits PA (1986) Social support as coping assistance. J consulting and clinical Psychology 54(4):416-423

37. Roberts KJ, Lepore SJ, Heleson V (2006) Social cognitive correlates of adjustment to prostate cancer. Psycho-Oncology 15(3):183192. doi:10.1002/pon.934

38. Bellizzi KM (2004) Generativity and posttraumatic growth in adult cancer survivors. Int J Aging hum Dev 58(4):267-287

39. Bellizzi KM, Blank TO (2006) Predicting posttraumatic growth in breast cancer survivors. Health Psychol 25(1): 47-56. doi:10.1037/0278-6133.25.1.47

40. Taylor SE, Klein LC, Lewis BP, Gruenewald TL, Gurung RA, Updegraff JA (2000) Biobehavioral responses to stress in females: tend-and-befriend, not fight-or-flight. Psychol Rev 107(3):411-429

41. Ross CE, Van Willigen MJ (1997) Education and the subjective quality of life. Health Soc Behav 38(3):275-297

42. Helgeson VS, Snyder P, Seltman H (2004) Psychological and physical adjustment to breast cancer over 4 years: identifying distinct trajectories of change. Health Psychol 23(1): 3-15. doi:10.1037/0278-6133.23.1.3 